\title{
QUENCH FRONT PROPAGATION IN THE ANNULAR CHANNEL
}

\author{
JAN ŠTĚPÁNEK*, VAClaV BlÁHA, VACLAV DostÁL \\ Faculty of Mechanical Engineering, Czech Technical University in Prague, Technická 4, Prague, Czech Republic \\ * corresponding author: j.stepanek@fs.cvut.cz
}

\begin{abstract}
Understanding the quench front propagation during bottom core reflooding is crucial for the effective cooling during the LOCA accident. The results presented in this paper were obtained on an experimental loop with an annular test section. The test section consists of a vertical electrically heated stainless steel tube with outer diameter $9 \mathrm{~mm}$ and length of $1.7 \mathrm{~m}$. The heated tube is placed inside a glass tube with the inner diameter $14.5 \mathrm{~mm}$. Water mass flux during the reflooding is in the range from $100 \mathrm{~kg} \mathrm{~m}^{-2} \mathrm{~s}^{-1}$ up to $140 \mathrm{~kg} \mathrm{~m}^{-2} \mathrm{~s}^{-1}$ and the initial wall temperature of the stainless steel tube is in the range from $250^{\circ} \mathrm{C}$ up to $800^{\circ} \mathrm{C}$. The presented results show the influence of the initial conditions on the quench front propagation and the complexity of the phenomenon.
\end{abstract}

KEYwORDS: quench front, rewetting, LOCA.

\section{INTRODUCTION}

Cooling of very hot surfaces is still not satisfactorily described area. The main difficulty of this kind of cooling is that coolant can't reach the hot surface because of a thin vapor layer generated between the hot surface and the coolant. This vapor layer acts as a thermal insulating gap and it prevents effective cooling. Heat transfer in this gap is much lower than in rewetted area. As the surface cools down, the vapor layer collapses and coolant rewetts the surface. A high heat transfer rate takes place at this moment. The location where coolant, for example water, rewetts the surface is called the quench front. Because of rapid cooling at the quench front, a heat accumulated in front of the quench front is conducted towards the rewetted area. This heat conduction accelerates the cooling of dry surface and it helps the quench front to advance forward [1. The speed of this rewetting advance is called the quench front velocity.

Quenching takes place in many technical applications such as steel hardening, cryogenic technology and many others. One of the most crucial applications is a nuclear reactor safety. This phenomenon is dominant for safety during core reflooding phase of LOCA (Loss-Of-Coolant Accident). The temperature of the fuel cladding rapidly rises up (over $1200^{\circ} \mathrm{C}[2]$ ) after blow-down phase. Then emergency core cooling system (ECCS) starts to pump relatively cold water into the core. As the water reaches the hot fuel rods quenching appears [3]. This complicates effective core cooling.

The quenching phenomenon has been solved analytically in many studies based on experimental data 4 . In these studies cooled geometry is usually divided into several regions. The most common approach divides the geometry into two regions. One region is dry region in front of the quench front. In this region a heat transfer coefficient is assumed as zero, i.e. adiabatic boundary condition. The second region is wet or rewetted region, where a heat transfer coefficient is taken as constant number [5]. This problem is then usually solved using Wiener-Hopf technique or heat balance integral method (HBIM).

There were many experimental efforts in the second half of 20th century. But many of these experiments were done for short geometries with limited range of initial wall temperatures [6]. The main goal of upcoming experiments is to cover wide range of initial wall temperatures, water mass flow rates and to describe effects of accumulated heat (different wall thickness and uneven tube heating) and geometrical elements such as spacer grids. In this paper a first set of experimental data is presented.

\section{Experimental LoOP}

For the purpose of quench front phenomenon investigation an experimental loop has been built. The loop consists of test section, DC power source, data acquisition system and variable hydraulic circuit. The test section is assembled from inner electrically heated steel tube and from outer glass tube. The steel tube is $1.7 \mathrm{~m}$ high and it is equipped with set of K-thermocouples (see TC1, TC2 and TC3 in Fig. 1). These thermocouples are in contact with inner surface of the heated tube. The thermocouples in the wall are not calibrated and its precision is then $\pm 2.5^{\circ} \mathrm{C}$ but the precision of these thermocouples is not important because temperature time gradient is measured. The spacing between thermocouples is $0.5 \mathrm{~m}$. The outer diameter of the steel tube is $9 \mathrm{~mm}$, its wall thickness is $0.5 \mathrm{~mm}$ and the tube is made of $\mathrm{X} 6 \mathrm{CrNiTi} 18$ stainless steel. The outer glass tube has inner diameter of $14.5 \mathrm{~mm}$ and its wall thickness is $1.75 \mathrm{~mm}$. It gives annular flow cross-section of $100 \mathrm{~mm}^{2}$. The test section is situated between lower and upper chamber. In these chambers are situated pressure sensors with accuracy of $0.5 \%$ FSO and calibrated class $2 \mathrm{~K}$-thermocouples. Initial wall temperature, water mass flow rate, lower chamber 
pressure, inlet temperature, power input and outer temperature of the glass tube $\left(\mathrm{TC}_{\mathrm{GL}}\right.$ in Fig. 1) are scanned during the experiment. The water mass flow rate is continuously measured by turbine flow meter. The precision of the flow meter is $\pm 3 \%$.

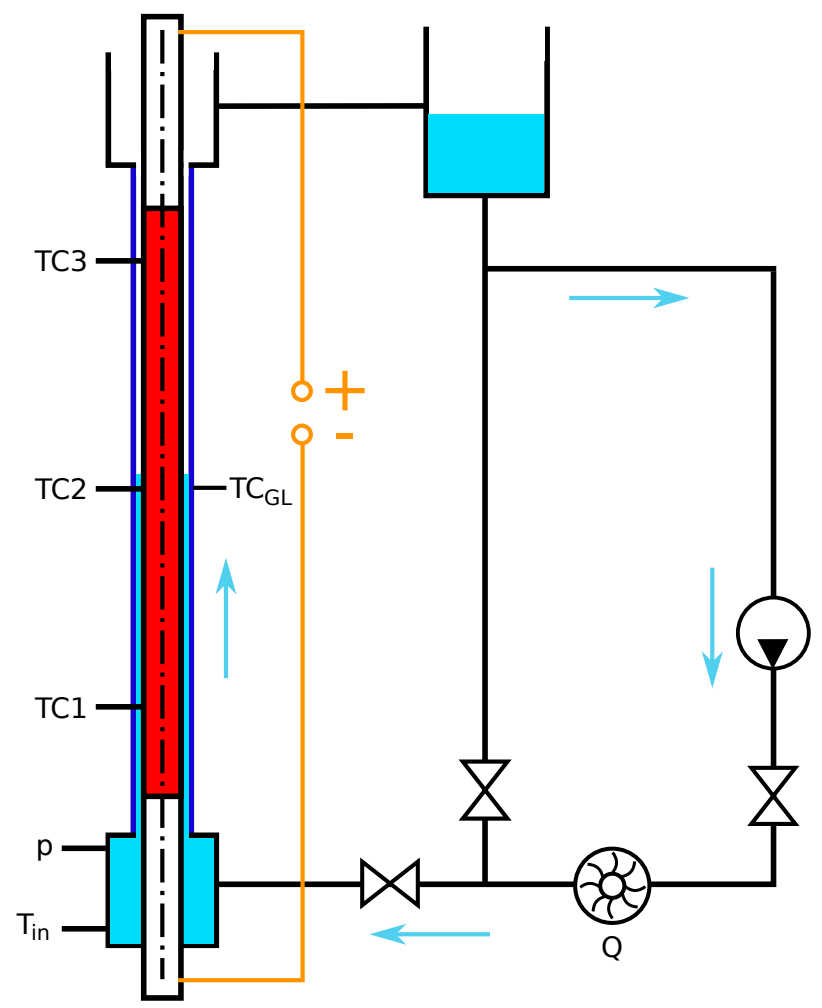

Figure 1. Simplified experimental loop scheme.

\section{Setup}

The initial wall temperature of the experiment was in range from $250{ }^{\circ} \mathrm{C}$ up to $800^{\circ} \mathrm{C}$ with step of $50^{\circ} \mathrm{C}$, the initial flow rate was set to $130 \mathrm{~kg} \mathrm{~m}^{-2} \mathrm{~s}^{-1}$ and its actual values are dependent on hydraulic characteristics of the test section during the experiment. This initial flow rate is adjusted in short circuit of the loop. Firstly the steel tube is heated up to desired temperature. The thermocouple on the glass tube is used as an indicator of the stationary state. When the temperature of this thermocouple is constant, the reflooding begins. Once the water reaches upper chamber, the experiment is finished. Collected information are then evaluated on the PC.

\section{Quench Front Velocity}

In experimental studies quench front velocity is usually identified in several ways. One of these approaches is usage of time dependence of measured temperature on the cooled geometry. Another approach for example uses optical methods such as high speed cameras. The Quench front velocity was obtained as the distance between thermocouples $(0.5 \mathrm{~m})$ overcame in measured time. Time, when a thermocouple has been rewetted is identified via maximum value of the first derivative of the measured temperature. This derivative value also represents position of the quenching temperature. When all rewetting times for each thermocouple are obtained, the quench front velocity can be calculated.

\section{Results}

Each experiment was repeated five times. The measured temperatures and other experimental data were interpolated using piecewise cubic hermite interpolation polynominal (PCHIP). The quenching temperature has been calculated as an average from valid experimental data. In Fig. 2 we can see the quenching temperatures for each initial wall temperature level and for each thermocouple.

As can be seen this dependence is almost linear. The rewetting temperature of the first thermocouple behind the inlet is highest and for the last thermocouple is this temperature the lowest of all. This temperature drop is caused by two-phase mixture propelled by steam generated at the quench front. This mixture precools dry region of the heated tube and this precooled surface is then rewetted at lower temperature. Initial wall temperature also strongly influences the value of the quench front velocity. Higher wall temperature generates more steam at the quench front. On the one hand this steam helps to cool down the dry region but on the other hand this steam generates higher pressure drop and this leads to lower quench front velocity. But the most significant slowdown is caused by evaporated fraction of the inlet water mass flux. This dependence can be seen in Fig. 3.

From Fig. 3 we can see, that quench front velocity drop is very significant between initial wall temperature levels $250{ }^{\circ} \mathrm{C}$ and $300^{\circ} \mathrm{C}$. From $300^{\circ} \mathrm{C}$ this dependence is almost linear. For $300^{\circ} \mathrm{C}$ the quench front velocity is $7.6 \mathrm{~cm} \mathrm{~s}^{-1}$ and for $800{ }^{\circ} \mathrm{C} 2.6 \mathrm{~cm} \mathrm{~s}^{-1}$. This velocity difference represents about $70 \%$ velocity drop in this temperature range. With higher wall temperatures a significant pressure bump can be observed when the water meets the hot surface in the test section. This prompt pressure increase is caused by rapid steam generation at the quench front. The steam moves at high speed along the hot surface and the steam is then slightly overheated. These conditions lead to high pressure drop along the test section and it slows the quench front down. The pressure drop can be observed from initial wall temperature of $400{ }^{\circ} \mathrm{C}$ and it grows from $2 \mathrm{kPa}$ up to $17 \mathrm{kPa}$ at $800{ }^{\circ} \mathrm{C}$ wall temperature level. The value of the pressure bump was calculated as a difference between maximum pressure and uninfluenced pressure at lower wall temperatures in the lower chamber. This dependence is plotted in Fig. 4. The maximum value of pressure bump at $800{ }^{\circ} \mathrm{C}$ represents nearly $90 \%$ of pressure drop of the fully reflooded test section.

Also heat transfer rate at the quench front has been calculated. This heat transfer rate is calculated using first derivative of the wall temperature and material characteristics of the heated tube such as 


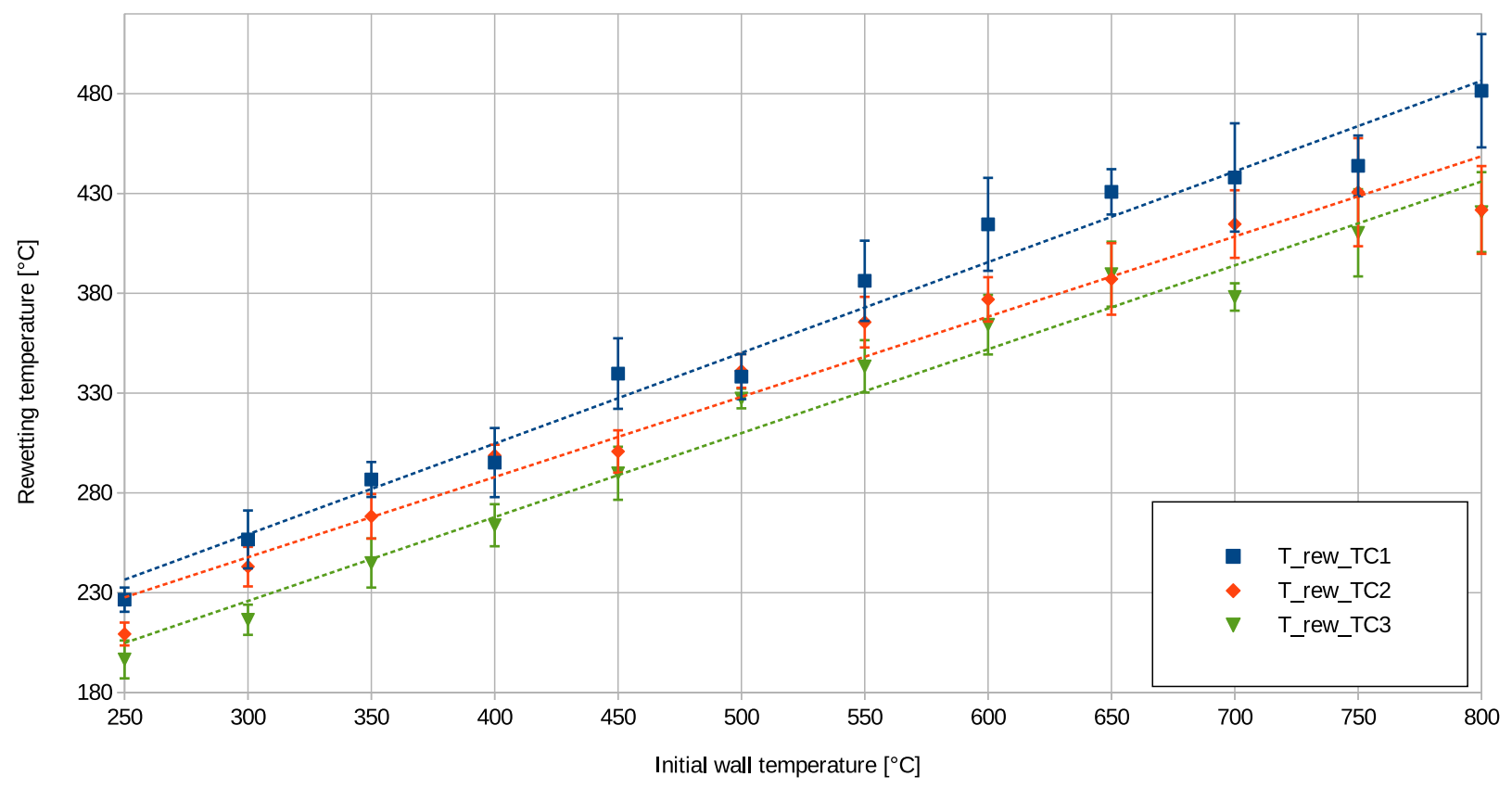

Figure 2. Rewetting temperature on initial wall temperature.

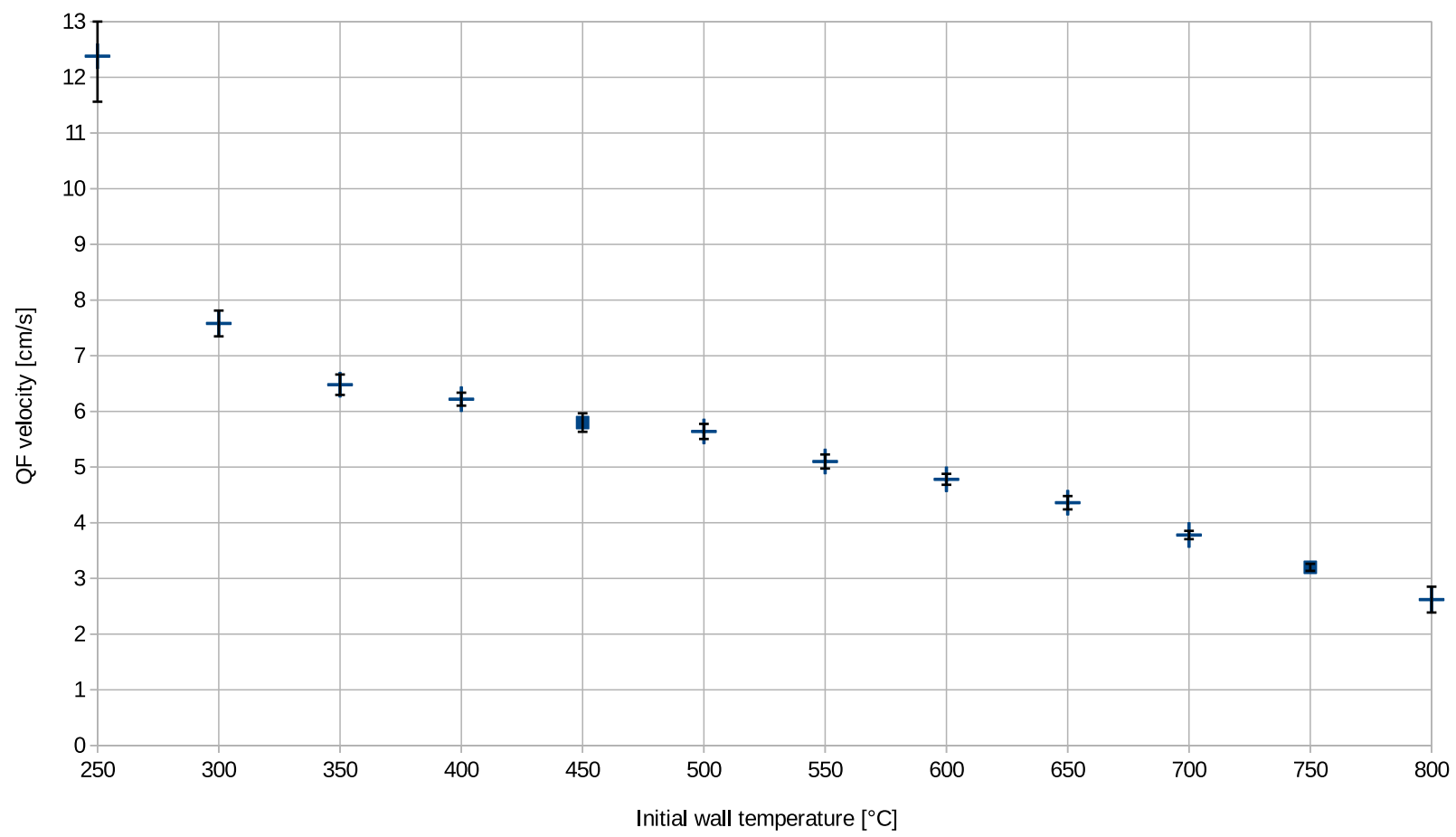

FIGURE 3. Quench front velocity on initial wall temperature.

heat capacity and electric resistance. Using known difference of accumulated heat and known value of electric current a heat transfer rate at the quench front can be enumerated. When the heat transfer rate is known, the heat transfer coefficient can be also obtained from this heat transfer rate and from known quenching temperature and temperature of saturated water. Resulting values of heat transfer coefficient are plotted in Fig. 5

\section{Experiment and Real Nuclear REACTOR}

The heated tube diameter corresponds to dimension of fuel rod of pressurized water reactor and its length is approximately halved. The results from the experiment give us the basis for estimating the quench front velocity as a local process. In a real nuclear reactor this process goes into complex spatial process. On the other hand a material used for the heated tube 


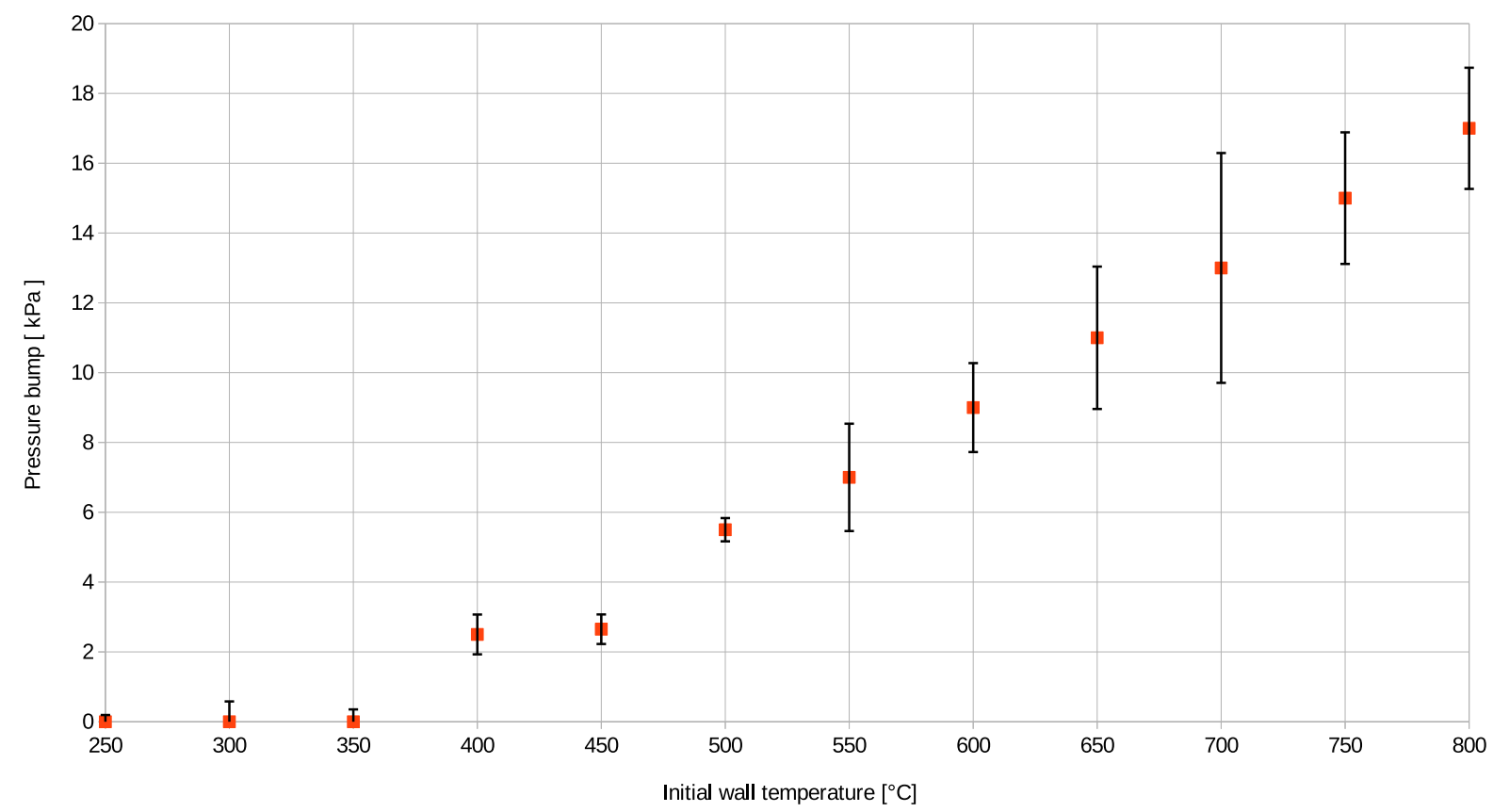

Figure 4. Pressure bump on initial wall temperature.

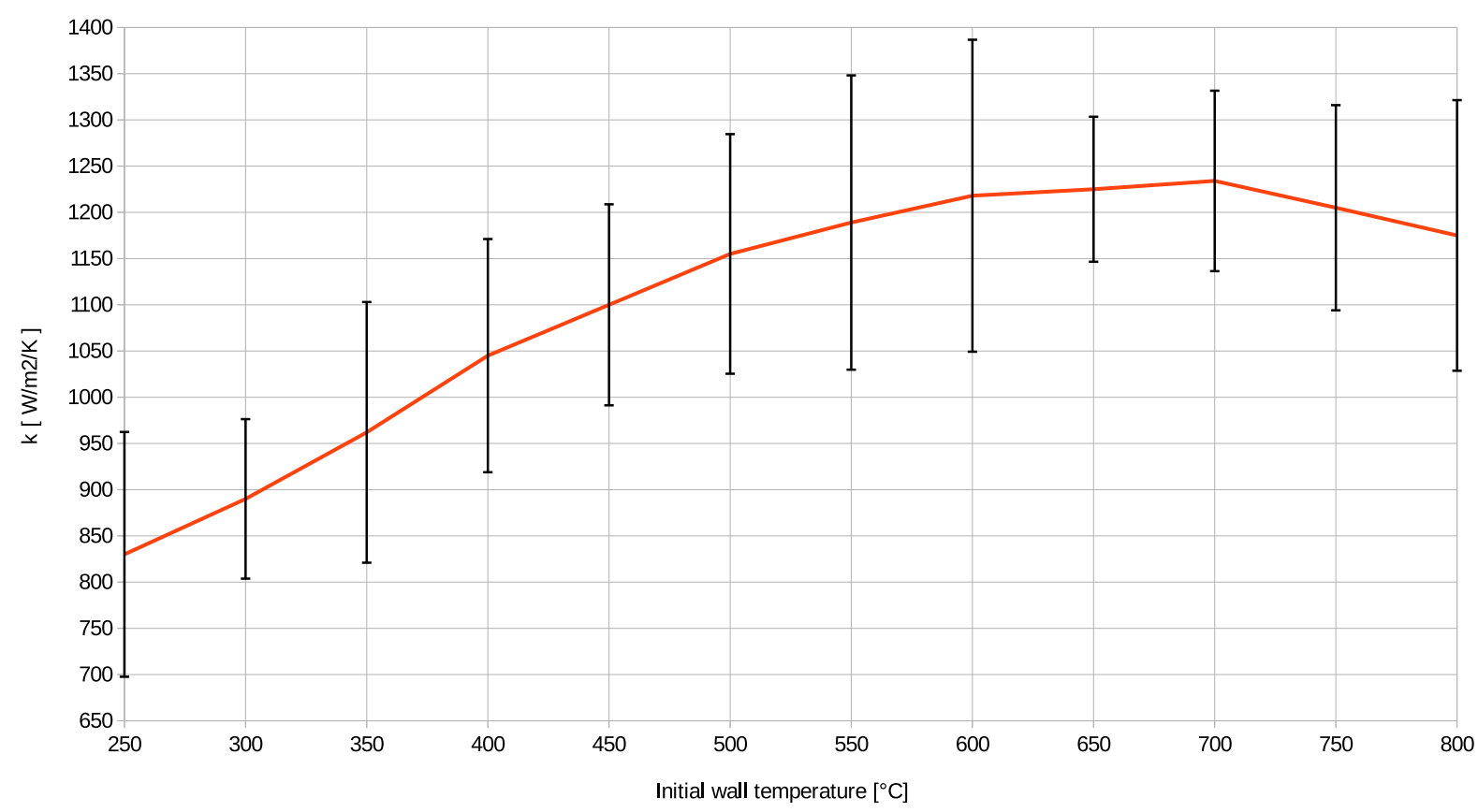

FIGURE 5. Heat transfer coefficient at the quench front on initial wall temperature.

also affects the quench front propagation. The use of zirconium alloy will probably significantly slow down the quench front propagation along the heated surface due to exothermic reaction of the zirconium and steam vapour approximately above $800{ }^{\circ} \mathrm{C}$ [7]. Inclusion of this phenomenon is necessary for experimental efforts at very high temperatures in the future. The heat generation along the tube is constant in this effort but also an uneven heat generation will be investigated in the upcoming experimental work. This unevenness will affect the quench front velocity as well.

\section{Conclusions}

The presented results in this paper show the complexity of the quenching phenomenon for one coolant mass flux level and for range of initial wall temperature from $250{ }^{\circ} \mathrm{C}$ up to $800^{\circ} \mathrm{C}$ in the annular channel. From these results can be concluded, that quenching velocities and rewetting temperatures are strongly dependent on the initial wall temperature. With increasing initial wall temperature the quench front velocity rapidly decreases. Moreover increasing initial 
wall temperature goes with significant pressure bumps. These pressure bumps strongly influence the hydraulic characteristic of the heated channel and this leads to a big pressure drop in the channel. These effects can lead to unevenness of water flow through the core during LOCA. The unevenness can lead to cooling water flowing around the central area of the core, where the surface temperature is lower, and the central area of the core can be cooled down distinctly later. On the other hand, geometrical elements, such as spacer grids, create secondary quench fronts moving along the fuel rod [8]. Due to these secondary quench fronts, the last rewetted point can't be clearly determined. In other words, the water presence above the core doesn't mean that the rest of the core is rewetted and cooled down. All these weaknesses of the quenching phenomenon should be uncovered for better handling of nuclear reactor accident. More experimental efforts will be done in the future. In these efforts a wide range of water mass flux will be covered.

\section{REFERENCES}

[1] E. Elias, G. Yadigaroglu. A General One DimensionalModel for Conduction-Controlled Rewetting of a Surface. Nuclear Engineering and design 42 (1977), 185-194.

[2] M. Billone, Y. Yan, T. Burtseva, R. Daum. Cladding
Embrittlement During Postulated Loss-of-Coolant Accidents. U.S. Nuclear Rerulatory Commision NUREG/CR-6967, ANL-07/04, 2008. http://www.nrc.gov/docs/ML0821/ML082130389.pdf

[3] H.C. Yeh. Analysis of Rewetting of a Nuclear Fuel Rod in Water Reactor Emergency Core Cooling. Nuclear Engineering and design 34 (1975), 317-322.

[4] S.K. Sahu, P.K. Das, S. Bhattacharyya. Analytical and Semi-Analytical Models of Conduction Controlled Rewetting: A State of the Art Review. Thermal Science 19 (2015), 1479-1496. DOI:10.2298/TSCI121231125S

[5] S. Olek. On the Two Region Model with a Step Change in the Heat Transfer Coefficient. Nuclear Engineering and Design 108 (1988), 315-322.

[6] A.K. Saxena, V. Venkat Raj, V. Govardhana Rao. Experimental Studies on Rewetting of Hot Vertical Annular Channel. Nuclear Engineering and Design 208 (2001), 283-303. DOI:10.1016/S0029-5493(01)00356-9

[7] J. Belle, M.W. Mallett. Kinetics of the High Temperature Oxidation of Zirconium. J. Electrochem. Soc. 101 (1954), 339-342. DOI:10.1149/1.2781278

[8] J. Stepanek, V. Blaha, V. Dostal, P. Burda. The Effect of Spacer Grid's Elements on the Rewetting Velocity. In Proceedings of International Conference on Nuclear Engineering (ICONE23). New York: ASME, 2015. ISBN 978-4-88898-256-6. 